Revista de la red interuniversitaria de estudios sobre las

literaturas rioplatenses contemporáneas en Francia

$9 \mid 2013$

Homenaje a Ana María Barrenechea

\title{
Algunas observaciones acerca de lo dicho y lo callado en Erec et Enide de Chrétien de Troyes
}

\section{María Silvia Delpy}

\section{OpenEdition}

\section{Journals}

Edición electrónica

URL: http://journals.openedition.org/lirico/1187

DOI: $10.4000 /$ lirico. 1187

ISSN: 2262-8339

Editor

Réseau interuniversitaire d'étude des littératures contemporaines du Río de la Plata

\section{Referencia electrónica}

María Silvia Delpy, « Algunas observaciones acerca de lo dicho y lo callado en Erec et Enide de Chrétien de Troyes », Cuadernos LIRICO [En línea], 9 | 2013, Puesto en línea el 01 septiembre 2013, consultado el 30 abril 2019. URL : http://journals.openedition.org/lirico/1187 ; DOI : 10.4000/lirico.1187

Este documento fue generado automáticamente el 30 abril 2019.

\section{cc) $(7)$}

Cuadernos LIRICO está distribuido bajo una Licencia Creative Commons Atribución-NoComercialSinDerivar 4.0 Internacional. 


\title{
Algunas observaciones acerca de lo dicho y lo callado en Erec et Enide de Chrétien de Troyes
}

\author{
María Silvia Delpy
}

A Anita,

cuya palabra abrió caminos y fortaleció vocaciones

1 Reflexionar sobre la palabra, sobre el discurso, en algunos textos de ficción de los siglos XII y XIII, nos conduce necesariamente a indagar sobre el silencio, percibido sea como simple impedimento comunicativo, como exclusión, consciente o no, del proceso de interrelación motivada, en algunos casos, por circunstancias no siempre fáciles de desentrañar.

2 Frente a esta circunstancia, resulta imposible soslayar, en los textos medievales, la permanente circulación de la palabra - la del narrador, la de los personajes, la de voces extratextuales - que deja su impronta a través de las más diversas facetas : como forma primera de aprehensión del mundo ${ }^{1}$, como desencadenante de la escritura misma del texto $^{2}$, como instrumento retórico afinado destinado a mover voluntades, como forma, aparente o no, de restaurar un orden desquiciado, como signo móvil que vehiculiza una realidad marcada por lo inconsistente y lo ambiguo. Paul. Zumthor (1987: 83) fue profundamente consciente de su importancia al afirmar que

L'idée, profondément ancrée dans les mentalités d'alors, de la puissance réelle de la parole, engendre une vue morale de l'univers. Tout discours est action physiquement et psychiquement effective.

3 Tal el sentido, sin duda, del antiguo proverbio medieval que, aunando cristianismo y viejas tradiciones paganas, evoca el misterioso poder que habita en la palabra : «In petris, herbis, vis est, sed maxima verbis ».

4 Y, por otra parte, ¿por qué motivos, implícitos o no, el héroe de algunos relatos anuda su lengua, no lo dice todo? El silencio ofrece una sorprendente gama de modulaciones: desde la exclusión impuesta de la palabra y el mutismo que surge por circunstancias 
oscuras que con frecuencia hunden su raigambre en el mito y el tabú, hasta el que se genera como producto de un juego de fingimientos y disimulos. Impuesto desde el exterior o surgido desde los aspectos más recónditos del sujeto, el silencio parece ser, en muchos textos medievales, la instancia ineludible por la que debe transitar aquel que emprende la vía purificadora de la aventura. ${ }^{3}$

El relato de la serie de peripecias que configuran los romans de Chrétien de Troyes, está precedido, en la mayoría de los casos, por un conjunto de consideraciones que componen un paratexto peculiar : el prólogo, en el cual, entre otras cosas, Chrétien define un decir poético (su decir poético) que, en el momento de la composición de Erec et Enide ${ }^{4}$, su primer roman (ca. 1070), no tiene mucho más de veinte años de existencia. ${ }^{5} \mathrm{Si}$ bien es cierto que esos prólogos no constituyen una disquisición sistemática sobre el arte del roman, no lo es menos que desde el comienzo mismo de dos de sus obras -Erec et Enide y Lancelote- aflora un esbozo de reflexión sobre el quehacer del escritor, sobre la triple vía de acceso a la palabra poética: la materia o invención, el sentido (san), que, más allá del significado literal, apunta a un valor de enseñanza, y la intraducible conjointure (o, más específicamente, bele conjointure), es decir, la adecuada organización de la materia narrada, aquello que transforma un conjunto precariamente estructurado, como puede serlo la transmisión oral de un relato, en un texto orgánicamente compuesto.

6 Así, en Erec et Enide, los veintiséis versos del prólogo insisten, a través de la voz del autor concretamente enunciada ("C'est pourquoi Chrétien de Troyes affirme», v. 9) 6 , en una serie de aspectos relacionados con el dictum poético : la necesidad de empeñarse « à bien dire et à bien enseigner » (v. 12) ${ }^{7}$, razón por la cual, el propio Chrétien transformará un cuento de aventura es decir, todas las potenciales versiones previas del relato, buenas o malas, existentes o no, en « une fort belle composition » (v. 14) ${ }^{8}$ a diferencia de quienes, para ganarse la vida, no temen destrozar y corromper los relatos que vehiculizan de corte en corte. Y, para finalizar, proclama la absoluta y gozosa confianza en su propia obra cuyo recuerdo « ... à tout jamais restera en mémoire, / autant que durera la chrétienté » (vs. 24-25).

7 A diferencia de otras obras de Chrétien en las que la anulación -temporaria- de la palabra se debe sea a una situación límite por la que atraviesa el sujeto ${ }^{10} \mathrm{o}$ a la presencia más o menos difusa de una falta inconsciente cometida por é ${ }^{11}$, en este texto, la palabra vedada proviene de una imposición, a primera vista arbitraria : la de Erec hacia su mujer Enide.

8 Si bien el análisis propuesto intentará centrarse en las diversas facetas de esta circunstancia central, no se puede, sin embargo, dejar de señalar brevemente otros aspectos que adopta el motivo de la palabra previos al punto que procuraremos estudiar. Desde esta óptica, creo que vale la pena destacar, al principio mismo del relato, la presencia incuestionable y casi sagrada de la voz de Arturo, quien, saliendo del mutismo y la taciturnidad en los que con frecuencia se encuentra sumido, anuncia la restauración de la antigua costumbre de la caza del ciervo blanco, a cuyo término el ganador deberá entregar un beso a la doncella más hermosa de la corte. Dentro de las reacciones suscitadas por los ecos de la voz real, tampoco puede pasarse por alto la conversión de la palabra en peligroso elemento de discordia ya que, en el seno mismo de la corte comienza a circular la parole male (v. 298), generada por el descontento de los barones, ninguno de los cuales está dispuesto a reconocer que su amada no será digna del beso a la más bella Sin embargo, el equilibrio volverá a restablecerse con la recuperación del valor de la voz del rey, de la palabra verdadera, del voir dire (vs. 1812 ss.) : con la aceptación del beso real merecido por Enide, circunstancia que pondrá fin a cualquier amenaza de desorden: 
«Seigneur, au nom de Dieu et de sa Croix./ vous pouvez en toute légitimité lui donner le baiser,/ car elle est la plus belle qui soit » (vs. 1817-1820) ${ }^{12}$.

Si bien todo lo señalado anteriormente pone de manifiesto el interés del narrador por los diversos efectos suscitados por la circulación de la palabra, el eje del texto queda constituido por la desdichada exclamación de Enide proferida poco después de su casamiento, quien, unos versos atrás, había sido descripta, sin embargo, como dama de sage dit (v. 2414). Inmersos en el paraíso del erotismo absoluto de los primeros momentos del matrimonio, enceguecidos por una pasión inmoderada a la cual, según teólogos y predicadores, es el marido quien debe poner freno, juicio y discreción, ya que la mujer es incapaz de gobernar sus afectos, $y$, sobre todo, prácticamente aislados de la convivencia cortesana, de los insoslayables vínculos sociales, ni el uno ni el otro advierten el peligro que esta circunstancia conlleva. Erec ha dejado de quebrar yelmos en los torneos, de destrozar lanzas, ganar caballos y abatir caballeros: "Il ne se souciait plus de tournoyer :/il allait vivre en amoureux auprès de sa femme, / il en fit son amie et son amante » (vs. 2433-2435) ${ }^{13}$. Paulatinamente, la palabra acusadora se disemina por la corte y va construyendo un discurso adverso a Erec : el héroe ha caído en la temible recréantise, es decir, en la traición a los ideales caballerescos, una de las faltas más graves en las que puede incurrir un caballero.

El rumor llega hasta los oídos de Enide quien intenta, por todos los medios, de mantenerlo callado. Silencio autoimpuesto que trata de preservar a Erec y tal vez, también, a sí misma. Pero de pronto, en una instancia en que el texto por primera vez parece manifestar concretamente la dualidad que los amantes parecían haber abolido a través del deseo y la admiración recíproca : «Il dormait, elle était éveillée» (v. 2475) ${ }^{14}$, el narrador nos alerta ante el momento en que Enide «se souvint de la parole / que la plupart des gens du pays/ disaient à propos de son seigneur » (vs. 2476-78) ${ }^{15}$. Y, sin poder contenerse, pronuncia lo que será el prólogo a la desgracia : «'Par quel malheur ai-je quitté /mon pays (...)/ quand le meilleur des chevaliers / (...)/ a pour moi abandonné sa condition ?"« (vs. 2492-2500) ${ }^{16}$. Unos versos más abajo, dirigiéndose a Erec, exclama aquello que parece subsumir dentro de sí todas las palabras hasta entonces dispersas por la corte : las palabras de los otros asumidas ahora por Enide : « C'est alors qu'elle lui a dit : 'Par quel malheur as-tu été là-bas ?'« (v. 2503) ${ }^{17}$.

11 Ello basta para despertar a Erec no solo de su sueño presente sino del sueño engañoso y mucho más profundo que parece haber sido hasta ese momento su vida con Enide. Dueño de una violencia hasta entonces desconocida, Erec obtiene, por fin, la confesión :

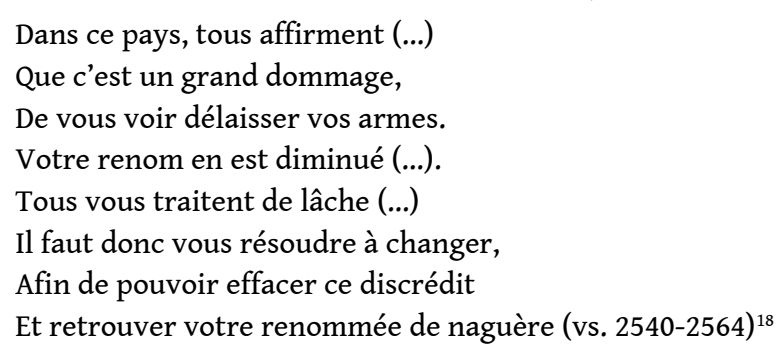

12 Tal vez sean éstas las únicas palabras que hasta ahora Enide haya pronunciado con entera independencia del discurso masculino, del de Erec. Tal vez por ello mismo, Enide no es capaz de tolerarlas y convierte su palabra en sinónimo de locura : « Seule, elle s'adresse à elle-même reproches et réprimandes/ pour la folle parole qu'elle a prononcée » (vs. 2582-2583) ${ }^{19}$, precisamente ella, la "dama de los dichos sabios". Tal vez Enide haya sido incapaz de asumir el poder de esa palabra - que ni siquiera es estrictamente suya -, 
incapaz de asumir su libertad y su valor y atribuyéndose un orgullo que nos resulta difícil de explicar: "'J'étais parfaitement heureuse, / Mais l'orgueil m'a rendue présomptueuse'«(vs. 2601-2602) ${ }^{20}$. Enide ha invadido, sin proponérselo, un terreno vedado. Al mismo tiempo, será ésta la palabra que habrá de generar la aventura central en cuya conjointure se intersectan el tiempo de la penitencia, el del silencio forzado, el de las pruebas -todas ellas sobre el plano del lenguaje - y, por último, el de la reconciliación.

No puede, sin embargo, negarse que Enide ha cometido un pecado de palabra ${ }^{21}$, una de aquellas faltas especialmente condenadas ya por San Benito en su Regla ${ }^{22}$ que los clérigos, a fines del siglo XII y principalmente a lo largo del XIII censuraron con severidad : la de la murmuración o la maledicencia, que tuvieron en las mujeres su principal agente de difusión.

La interdicción de Erec es terminante: ambos deben abandonar la corte y Enide es condenada al silencio : "Puis il se prend à la menacer : /que désormais elle n'ait plus l'audace/ de proférer un seul mot de sa bouche/ à moins qu'il ne lui en donne la permission » (vs. 2914-2917) ${ }^{23}$. No solo Erec corta simbólicamente la lengua de Enide sino que corta también toda posibilidad de contacto, quiebra los cimientos de la comunicación entre ambos y, al mismo tiempo, con la sociedad cortés, por lo cual cabría preguntarse si la condena a Enide por el mal uso de la palabra no se hace también coextensiva a la corte artúrica.

Se inicia así una larga serie de aventuras que, en el estricto plano de la narración, se desarrollarán de manera similar. Enide, convertida en los ojos y oídos de Erec, trata, una y otra vez, de ponerlo sobre aviso acerca de los peligros que se avecinan, infringiendo de ese modo el mandato impuesto y provocando la consiguiente ira de Erec. Los peligros se vuelven cada vez mayores, la lucha de Enide contra su propia palabra, cada vez más violenta. Mientras tanto, el narrador sigue anudando su conjointure, y, en un registro distinto, repite el emblemático « Il dormait, elle était éveillée » (v. 2475) ${ }^{24}$, preludio a todo el conflicto y señal del permanente estado de alerta de Enide. En medio de una nueva y dolorosa vigilia, los reproches de Enide hacia sí misma son cada vez mayores : incapaz de tomar distancia de las amenazas de Erec y sintiéndose culpable de haber osado repetir aquello que llegó a poner en duda el valor de su marido, maldice su propia lengua: « Honnie soit ma langue/ pour avoir proféré ces propos orgueilleux et outrageants » (vs. $3112-3113)^{25}$.

16 La prueba del silencio parece, sin embargo, haber aguzado la astucia de Enide : hay tal vez ahora en ella, algo más que "sabias palabras". Requerida de amores por el conde Galoain, la comunicación con el exterior, interrumpida desde un tiempo impreciso, resurge afinando su ingenio y su astucia. Tan sinceras parecen ser sus palabras alentando al conde felón a poner fin a los días de Erec, que el narrador no puede evitar entrometerse, quebrando, él también, su propio silencio : «Le cœur ne pense ce que bouche dit» (v. $3380)^{26}$. Su palabra será, ahora, palabra salvadora. Y una vez más resurge esa melodía mínima que parece ir señalando los momentos decisivos de la narración : «Elle ne ferma pas l'œil de la nuit, /pour son seigneur elle reste en éveil » (vs. 3441-3442) ${ }^{27}$. Erec duerme, no ve, no sabe. Enide, dueña ya de su palabra, la ha convertido en instrumento de salvación.

Paralela a la violencia de los sucesivos encuentros con enemigos diversos, crece en Enide la fuerza del conflicto interno entre el callar y el hablar. Ante la amenaza encarnada por Guivret el Pequeño, enfrentado a Erec a lo largo de una extensa aventura (vs. 3659-3926), 
la frustración de Enide suscitada por el mutismo obligado llega a su punto culminante en la llamativa representación del combate interior entre el silencio y la palabra, concretada en la escritura a través de una serie de imágenes que hacen de la palabra reprimida, sofocada, un elemento cuyo peso y materialidad resultan llamativos y que convierten la boca de Enide en un verdadero campo de batalla :

Elle ne sait quel parti prendre, parler ou se taire.

Elle prend conseil en elle-même ; souvent elle est tout près de parler et sa langue se met en mouvement, mais la voix ne peut sortir, car la peur lui fait serrer les dents et tenir enclose la parole. (vs. 3723-3733) ${ }^{28}$

Coincidiendo con esta situación, por primera vez, el discurso del narrador revela la interioridad de Erec, quien suelta su secreto $\mathrm{y}$ abre compuertas hasta ahora aparentemente clausuradas :

Elle lui parle, il la menace,

mais n'a aucune envie de lui faire du mal,

car il voit bien et comprend

qu'elle l'aime par dessus tout

et que lui la chérit de tout son cœur. (vs. 3761-3765) ${ }^{29}$

Hilvanadas unas tras otras, las aventuras van configurando un destino que dará al héroe, o a los héroes, su verdadera dimensión. Y es precisamente próximo a una de las últimas pruebas, cuando Enide, convencida de la muerte de Erec luego de un encuentro especialmente sangriento con el conde de Limors y a punto de ser desposada por la fuerza con éste, parece, al mismo tiempo, descubrir el límite extremo al que la condujo su palabra imprudente, aquella que desencadenó la larga vía purgativa y que reintegra al receptor al comienzo de la aventura de los esposos :

Hé! qu'ai-je donc dit ? Par quel égarement

ai-je proféré la parole qui a entraîné la mort de mon seigneur,

la parole mortellement empoisonnée

dont il faut m'accuser ! (vs. 4638-4641) 30 $^{30}$

Incapaz de tomar distancia, asume como propia la ya lejana palabra de los barones de la corte y reitera el sonido fúnebre de la frase que desencadenó el conflicto, dirigida, ahora, a Erec : « 'Hé ! Dist-ele, com mar i fus'« (v. 4631). ${ }^{31}$

El desenlace no está lejano, y es preciso hacer justicia a Enide. Ante la violencia de las intenciones del conde, sus gritos arrancan a Erec de su falsa muerte quien, luego de matar al señor de Limors, logra salir del castillo llevando en grupa a su mujer, bajo el claro de luna. Enide recibe el perdón que le han valido todas las pruebas a las que fue sometida respecto de las cuales Erec no manifiesta el menor arrepentimiento - y volverá a ser amada con más pasión que nunca : "Maintenant Erec ne peut rien lui reprocher ;/ il l'a bien éprouvée/ et quel grand amour il a trouvé en elle !» (vs. 5128-5130) ${ }^{32}$.

Asimismo, es preciso señalar que, fuera del molde habitual del relato artúrico, en Erec et Enide el protagonismo es doble : ambos logran sellar una nueva unión, surcada a la vez por la sensualidad y el sufrimiento compartidos :

A cette heure, elle connaît les enlacements, les baisers

et tout ce qui peut la combler d'aise.

A cette heure, elle connaît la joie et la jouissance,

ils sont maintenant tous deux nus dans un même lit 
et échangent embrassements et baisers,

ils ne connaissent plus grand délice.

Combien de malheurs et d'infortunes n'ont-ils pas connus,

lui pour elle et elle pour lui?

A cette heure, ils ont achevé leur pénitence. (vs. 5237-5245) (33 $^{33}$

El ingreso al mundo de la maravilla - hasta ahora ausente del relato - clausura la serie de aventuras de la pareja. Dentro de un vergel rodeado de muros de aire y convertido en prisión, el caballero Mabonagrain y su amiga se hallan encerrados en la cárcel de un amor egoísta y aislado - similar, tal vez, al de Erec en sus primeros momentos de pasión- del cual, por decisión de la doncella, no saldrán hasta la llegada del caballero capaz de vencer a Mobonagrain. Erec, atraído a la vez por el peligro extremo, ya que se trata de « l'aventure d'où personne ne peut sortir/ sans subir honte ni abjection » (vs. 5437-5438) (44 $^{34}$ $\mathrm{y}$, a la vez, por la seducción que ejerce su nombre - la Joie de la cort -, obtiene su triunfo más resonante: aquel que liberará a la pareja de ese ámbito de asfixiantes encantamientos. Pero hay algo más, congruente con la coherencia interna del texto : la confirmación de Enide en su carácter de heroína. Redimida por sus propios méritos de una presunta falta, liberada de un silencio impuesto no sin cierta crueldad, logra, gracias al "bien dire et bien enseigner" 35 de su palabra liberada, hacer volver al receptor a la voz del narrador presente en la apertura de la narración, devolver la dicha a la doncella del vergel y restablecer definitivamente la alegría en la corte de Brandigan.

\section{BIBLIOGRAFÍA}

Casagrande, Carla y Vecchio, Silvana. Les péchés de la langue. Paris : Ed. du Cerf, 1991.

Cerquiglini, Bernard. La parole médiévale. Paris : Éditions de Minuit, 1981.

Chrétien de Troyes. Le conte du Graal. Paris : Champion, 1984.

Chrétien de Troyes. Le Chevalier au Lion (Yvain). Paris : Champion, 1971.

Chrétien de Troyes. Erec et Enide. Édition critique d'après le manuscrit B.N. Fr. 1376. Traduction, présentation et notes de Jean-Marie Fritz. Paris : Lettres Gothiques, 1992.

James Raoul, Danièle. La parole empêchée dans la littérature arthurienne. Paris : Champion, 1997.

La Regla de San Benito. Madrid : Biblioteca de Autores Cristianos, 2006.

Zumthor, Paul. La lettre et la voix. De la "littérature" médiévale. Paris : Editions du Seuil, 1987.

\section{NOTAS}

1. Tal el caso del diálogo entablado entre el joven Perceval y los caballeros al comienzo del relato durante el encuentro que marcará el rumbo de su vida. Voir Le conte du Graal. Paris : Champion, 1984 , vs. $100-361$. 
2. Voir en Yvain, el relato puesto en boca de Calogrenant, al inicio de la narración, que actúa como disparador de la aventura del protagonista. Cf. Le Chevalier au Lion (Yvain). Paris : Champion, 1971, vs. 173-579.

3. Para un tratamiento pormenorizado del tema voir Danièle James Raoul 1997.

4. Chrétien de Troyes, Erec et Enide. Édition critique d'après le manuscrit B.N. Fr. 1376. Traduction, présentation et notes de Jean-Marie Fritz. Paris : Lettres Gothiques, 1992.

5. Los romans pertenecientes a la matière antique (Roman de Thèbes, Roman de Troyes, Roman d'Enéas) comienzan a surgir a partir de 1150 aproximadamente.

6. «Por ce dit Crestiens de Troies"

7. « A bien dire et a bien aprendre ».

8. «Une mout bele conjunture»

9. «Que toz jors mais iert en memoire/ tant que durra crestïntez »

10. Como en el caso de Yvain, en El caballero del león, quien, luego de haber perdido el amor de Laudine, su esposa, por no respetar el plazo fijado para intervenir en justas y torneos : "Yvain ne peut lui répondre/ car le sens et la parole lui font défaut » (vs. 2774-2775).

11. Como en el caso de Perceval en Le conte du Graal, cuyo pecado, consistente en el abandono de su madre viuda para partir en búsqueda de aventuras, lo vuelve mudo en la escena crucial del Grial y le impide formular las preguntas que podrían restaurar la fertilidad de la Tierra Baldía y la salud del Rey Pescador.

12. «Tuit s'escrïent a une voiz :/ 'Sire, por Deu et por sa croiz, /Baisier la poez bien par droit,/ car c'est la plus bele qui soit'».

13. « N'avoit mais soing de tornoier : a sa fame aloit dosnoier, / De li fist s'amie et sa drue ».

14. «Cil dormi et cele veilla».

15. « De la parole li membra/ Qui disoient de son seignor/ Par la contree li plusor».

16. « Et dit : 'Lasse, con mar m'esmui/ de mon pays !(...)/Quant toz les mieudres chevaliers, /(...)/ A de tout en tout relinquie/ Por moi toute chevalerie'«. Para la utilización y los valores del adverbio mar, reiterado una y otra vez en el texto para subrayar los momentos de mayor pesadumbre de Enide, voir Bernard Cerquiglini 1981 : 128-162.

17. « Lors li a dit :'Con mar i fus!'«

18. «'Par ceste terre dient tuit, (...)/Que granz damages est de vos/que vos armes entrelessiez. / Vostre pris en est abaisiez (...)/ Recreant vos apelent tuit (...)/ Autre consoil vos convient prendre,/ Que vos puissiez cest blasme esteindre/ Et vostre premier los ateindre'« .

19. «A li soule tense et estrive/ De la folie qu'ele dist ».

20. "'Moust estoie bien euree, /Mais trop m'a orgueuz sozlevee' »

21. Voir Carla Casagrande y Silvana Vecchio 1991.

22. «Faciamus quod ait Propheta : 'Dixi : custodiam vias meas, ut non delinquam in lengua mea; posui ori meo custodiam.’ («Cumplamos nosotros lo que dijo el profeta: 'Yo me dije : vigilaré mi proceder para no pecar con la lengua. Pondré una mordaza a mi boca.'») La Regla de San Benito, VI, 1.

23. «Et si la prent a menacier/Qu'ele ne soit mais tant hardie/ C'un sol mot de boche li die, / Se il ne l'en done congié. »

24. «Cil dormi et cele veilla».

25. «Honie soit ma langue toute, / Qui l'orguil et l'outrage dist».

26. «Et pense cuer que ne dit boche ».

27. «Onques la nuit ne prist somoil,/ Por son seignor est en esvoil ».

28. "Qu'ele ne set le quel saisir, / Ou le parler ou le taisir./ A li meïsmes se consoille ; / Sovant dou dire s'aparoille,/ Si que la langue s'en esmuet,/ Mais la voiz pas issir n'en pue,/ Car de paor estraint les danz,/ S'enclot la parole dedanz./ Ensi se justise et destraint :/ La boche clot, les denz estraint, / Que la parole fors n'en saille. » 
29. «Ele li dit ; cil la menace, / Mais n'a talant que mal li face,/Qu'il aperçoit et conoist bien/ Qu'ele l'aimme sor tote rien,/ Et il li tant que plus ne puet. »

30. «He, qu'ai-je dit? Trop ai mespris, /que la parole ai esmeüe/ Dont mes sire a mort reçeüe, / La mortel parole entochie/ Qui me doit estre reprochie'" .

31. Recordar v. 2503 : « Lors li a dit : ‘Com mar i fus !'«

32. "Or ne li set que reprochier/ Erec, qui bien l'a esprovee :/ vers li a grant amor trovee. »

33. «Or fu acolee et baisie/ Or fu de toz biens aasie, / Or ot sa joie et son delit./ Or sont nu a nu en un lit, / Et li uns l'autre acole et baise ; /N'est rien nule qui tant lor plaise./ Tant ont eu mal et ennui, / Il por li et ele por lui,/ Or ont faite lor penitance. »

34. «'L'aventure dont nuns n'estort/ Qu'il n'i reçoive ou mort'».

35. Cf. Prólogo, vs. 11-12 « Doit chascuns penser et entendre/A bien dire et a bien aprendre ».

\section{RESÚMENES}

A diferencia de otros textos de Chrétien en los que la anulación de la palabra se debe sea a la presencia de un tabú o de una falta cometida por el sujeto respecto de su entorno, en Erec y Enide ésta se genera por una imposición, a primera vista, arbitraria.

El análisis intenta estudiar los diversos recursos puestos en juego por la palabra y las facetas que adopta a lo largo del texto teniendo en cuenta, fundamentalmente, la palabra de Enide como factor desencadenante de la aventura. A primera vista, el texto parecería insertarse dentro de la larga cadena de escritos que inscriben a la mujer como sujeto del empleo inevitable de la palabra inoportuna. Si bien esta circunstancia no resulta aplicable al texto estudiado, Enide no logra escapar, aparentemente, de ese desborde de la palabra, transformado con frecuencia en una utilización perversa del lenguaje, tal como fuera insistentemente señalado por los clérigos medievales.

À la différence d'autres textes de Chrétien où le bannissement de la parole est dû soit à la présence d'un tabou, soit à une faute commise par le sujet envers son entourage, dans Erec et Enide cette circonstance surgit d'une imposition apparemment arbitraire.

Cette analyse s'applique à examiner les différentes ressources mises en jeu par la parole et les diverses modulations qu'elle adopte, en tenant compte, principalement, de la parole d'Enide en tant que facteur susceptible de déclencher l'aventure. À première vue, le texte parait s'insérer au sein de la longue chaîne d'écrits qui présentent la femme comme sujet inévitable de l'emploi de la parole importune. Bien que cette circonstance ne soit pas applicable au texte étudié, Enide ne peut apparemment échapper au débordement de la parole, transformé souvent en un emploi pervers du langage, tel que l'a signalé la voix des clercs au Moyen Âge.

Unlike other works by Chrétien where speech is suppressed due to the presence of a taboo or a fault committed by the individual vis-à-vis his environment, in Erec et Enide, speech is suppressed by an imposition, which seems, at first sight, arbitrary.

The article seeks to examine the speech motif and the different facets it shows throughout the text, focusing mainly on Enide's speech as a trigger to the adventure.

Initially the work appears to be included in the long chain of texts which present women inevitably using speech either erroneously or mischievously. Although this is not the case in this 
work, Enide does not seem to escape from this "eloquence", which often turns into a deviant use of language, as it was insistently pointed out by medieval clerics.

ÍNDICE

Mots-clés: littérature médiévale, Erec et Enide, parole importune, bannissement de la parole, roman

Keywords: medieval literature, Erec and Enide, mischievous speech, suppressed speech

Palabras claves: literatura medieval, Erec y Enide, palabra inoportuna, anulación de la palabra

\section{AUTOR}

MARÍA SILVIA DELPY

Universidad de Buenos Aires. CONICET

msdelpy@hotmail.com 